\title{
CORRESPONDENCE
}

\section{Six Types of Research}

SIR,--Rothschild correctly points to the importance of the question, "What is the object of the classification?" but fails to recognize that different people and organizations have different needs of a classification, so that the same classification may not suit them all. Moreover, by defining strategic research as part of applied research, he makes useful analysis impossible, and he also mixes categories in his classification: classification by research type (applied, strategic or fundamental) is independent of the classification productprocess-operations.

Because Rothschild refers to some of the terms we use, we would like to explain how we arrived at them. Our aim has been to classify the ARC's research in such a way that one can ask either very broad questions (for example, "What are we spending on cattle?") or much more detailed ones (for example, "What strategic reproductive physiology projects are there, related to an applied project on the improvement of techniques of artificial insemination?"). By using a matrix system and classifying each project by a number of independent categories, one can retrieve the information in many different ways, and in small or in large aggregates.

Our approach, unlike most others, has been, and continues to be, empirical. We tested our initial system on the 1,000 projects listed in our Index (Index of Agricultural Research, Agricultural Research Council, 1969). Our type category then contained four varieties, corresponding to applied, strategic, fundamental ("pure") and service. (The latter, not mentioned by Rothschild, covers such things as analytical or statistical services.) As we found that more than half of the ARC's work was strategic, and that it varied very much in character, some of it being closely linked with applied work and some of it not, we decided that it might prove useful to subdivide strategic research.

On the basis of experience we devised a more sophisticated classification system (A Revised Classification System of ARC Research, Agricultural Research Council, Planning Section Report No. 2, July 1972), again based on the matrix principle, and have used it to code all of the ARC's current 3,000 projects. Our type category now includes seven varieties. In addition to service, development, applied, and fundamental, there are three varieties of strategic research.

(1) Strategic A: research which is required to provide understanding of a current applied project; strategic $\mathbf{A}$ workers either form part of the applied project team or work very closely with it.

(2) Strategic B: research carried out with the main aim of understanding some particular aspect of agriculture in order to generate specific applied projects.

(3) Strategic C: research of an openended nature (with regard to application, not time as Rothschild states), but which is likely to further the scientific understanding of agriculture.

The point of subdividing in such a way is that one can aggregate as required. For example, the Parliamentary Select Committee asked the Research Councils to say what proportion of their research was spent on different types. From the definitions they gave it was possible to equate their varieties with ours, as follows:

\section{Select Committee \\ ARC \\ Applied \\ Oriented-strategic Strategic A \\ Basic-strategic Strategic B and C \\ Basic \\ Fundamental}

(Readers may find it instructive to compare the replies given by the various Research Councils to the Select Committee's question [First Report from the Select Committee on Science and Technology-Research and Development, xxxv-xlviii inc., HMSO, 237 ; 1972].)

Is it possible to suggest a basic classification which would be widely applicable?. If one eliminates from Rothschild's Table 2 those items which logically belong to a different classification category altogether we are left with the following:

\begin{tabular}{cc}
\multicolumn{2}{c}{ Research } \\
\cline { 2 - 3 } Pure research & Applied research \\
& Strategic research
\end{tabular}

This does not seem very useful. It would be surprising if most organizations could not use five varieties as a basis: service, development, applied, strategic and fundamental. (Whether one prefers the term pure, basic, or fundamental is entirely subjective ; many object to "pure", because of the implied impurity of non-"pure" research.) Of course, some organizations may do no fundamental work, others no development, and these could then simply be omitted. Our classification has been designed with the particular needs of agricultural research in mind and not with a view to universal adoption. Each organization can subdivide any one type of research according to its own particular needs.

$$
\begin{aligned}
& \text { T. L. V. ULBRICHT } \\
& \text { F. H. DODD } \\
& \text { W. S. WISE }
\end{aligned}
$$

Planning Section,

Agricultural Research Council, 160 Great Portland Street, London $W 1 N 6 D T$

\section{Strategic Research}

SIR,-Rothschild's Table 2 (Nature, 239,373 ; 1972) may well represent the point of convergence of a protracted dispute, and certainly those who are engaged on long-range research, and yet do not object to its acquiring an ultimate application, will welcome his adoption of the term "strategic" for their activity.

It is a pity that his Glossary defines strategic research as "Research undertaken to generate specific applied programmes". Although the spirit of this seems right, the term "enable" could advantageously have been substituted for "generate", or alternatively the words "the preconditions of" inserted.

The point is not academic, as can be illustrated with the aid of a topical example. Work in a number of laboratories devoted to machine intelligence research, including that at Edinburgh, is concerned among other things with how to program computer-controlled robots to carry out tasks of assembly and/or navigation. Such studies will, without question, help to make feasible -i.e., will "enable"-NASA's "Mars Rover" project inter alia. However, this applied programme cannot possibly be generated by the research, but only by the skill and force of NASA's approach to Congress. Meanwhile, in case the approach succeeds, NASA has begun to create a relevant research base at the Jet Propulsion Laboratory, Pasadena. If this is to be termed "strategic" (as it surely must be) then similar research at Stanford, MIT, and Edinburgh is presumably also "strategic". The scientists concerned see it in this light and are aware that 